\title{
Radiological findings in seropositive juvenile chronic arthritis (juvenile rheumatoid arthritis) with particular reference to progression
}

\author{
R A WILLIAMS AND B M ANSELL \\ From the Juvenile Rheumatism Unit, Canadian Red Cross Hospital, Taplow, UK
}

SUMMARY The radiological effects of peripheral joint disease in 81 patients with seropositive juvenile chronic arthritis were studied retrospectively with an average length of follow up of 11 years. The patients comprised 63 girls and 18 boys with average ages of onset being 10.7 years and $12 \cdot 1$ years respectively. All had developed positive serology within the first year of the disease. $X$-rays available in 70 of these patients at five years from onset of the disease showed erosive change to be present in all but three. The sites most commonly affected included the carpus, the metacarpal, the metatarsal, and interphalangeal joints, though a third of the patients also showed erosive change in large joints such as hips, knees, or shoulders. Between five and 10 years after disease onset progression of $x$-ray changes was evident in most patients, with additional joints becoming involved in about one third, though the distribution of joints was similar. After 15 years or more of disease the radiological changes tended to be more stable, but various mechanical difficulties often secondary to poor growth and degenerative change and to primary destructive inflammatory arthritis were evident. No specific drug regimen was found to have been universally effective in suppressing disease, and the frequency of side effects was a significant factor in preventing treatment schedules being maintained for long enough to be effective.

The heterogeneity of chronic arthritis in childhood is now well recognised with groups becoming characterised through their patterns of disease, associated conditions, and prognosis. ${ }^{1} 2$ Some $8-10 \%$ of children with chronic arthritis can be distinguished by showing a persistent seropositivity for IgM rheumatoid factor. Their disease is usually a symmetrical polyarthritis, similar to seropositive rheumatoid arthritis in adults and also has immunogenetic similarity. ${ }^{3}$ Patients with seropositive disease tend to be older children, have persistent activity, and develop early erosions.'

This present analysis is retrospective and looks at the pattern and severity of radiological joint destruction in such children after five years or more of disease, with attention also being paid to therapy with disease modifying drugs.

\footnotetext{
Accepted for publication 14 March 1985.

Correspondence to Dr R A Williams, Department of Rheumatology and Rehabilitation. Derbyshirc Royal Infirmary. London Road, Derby DE1 2QY.
}

\section{Patients and methods}

Patients were required to have persistent IgM rheumatoid factor present in the serum during the first year of their illness and to have had documented follow up for at least five years. Seropositivity was measured by the differential agglutination test, with titres equal to or greater than $1 / 16$, or by an equivalent agglutination test.

Eighty-one such patients were studied retrospectively. They comprised 63 girls and 18 boys with average ages of onset of $10 \cdot 7$ years and $12 \cdot 1$ years respectively (range 16 months to 15 years). Patients were reviewed at five-year intervals after onset of disease. The length of assessment averaged 11 years (range five to 30 years), with most information being gained from the five-year follow-up group which numbered 70 . In the 10 -year follow-up group there were 41 patients, 32 of whom had formed part of the five-year group, and for these patients sequential $x$-ray films were available. Smaller groups seen at 15 
years and at later periods after onset were also identified.

Radiographs, most commonly of the hands, were reviewed at approximately five-year intervals from disease onset by a single observer. Films had been taken over three decades and were of variable quality so that only gross changes were recorded. These included serious loss of joint space, bony erosion, complete destruction of normal joint structure by erosion, and bony fusion of the joint. Replacement of the hip or knee was also recorded. Reference to standard radiographic plates was made where required, particularly for abnormalities of growth. ${ }^{4}$ Not all patients had a full series of joint $x$-rays for assessment, so that any films not taken or unavailable for reading were marked as absent.

Major drug therapy such as gold, penicillamine, chloroquine, corticosteroids, or cytotoxic agents was recorded for the first 15 years of disease, and any side effects requiring cessation of treatment were noted. The use of these drugs in relation to serial $x$-ray changes was also studied.

\section{Results}

RADIOLOGICAL CHANGE FIVE YEARS AFTER ONSET

The distribution of joints showing any radiological abnormality favoured hands and feet, with joint erosions forming a considerable part of these changes (Table 1). The changes were usually symmetrical. All but three patients were affected by erosive disease. The commonest joint eroded was the wrist, which was affected at the carpometacarpal $(\mathrm{CMC})$, intercarpal, or proximal wrist joint levels in
59 of 70 patients. The commonest pattern of erosive disease affected the hand (Fig. 1), where the wrist. and metacarpophalangeal (MCP) joint were affected in 41 patients. In 19 of these patients the proximal interphalangeal (PIP) and distal interphæ langeal (DIP) joints were also eroded. In contrase small finger joint erosions occurred without wrisp erosions in only four patients. The wrist and MC尽 joints were the common early sites affected by erosions and also the sites of the most severe change, with three patients showing complete destruction of the MCP joint. In the feet the pattern of joint disease was similar to that found in the hane (Fig. 2), but the changes were often less severg Erosion of the hip or knee joint was present in 39 out of 70 patients (Fig. 3) and, in addition to the abnormalities noted in Table 1 , joint replacemen had been made in eight hips of five patients.

HAND X-RAY CHANGES OBSERVED AT FIV AND 10 YEARS FROM ONSET OF DISEASE $\vec{\longrightarrow}$ The 32 serial $x$-ray films of the hands and wris taken in anteroposterior projection showed furth narrowing of joint space in all but one patient an further erosive change in all but two (Fig. 4 to Deterioration was severe in seven patients widespread joint destruction. Fifteen patients showed moderate changes with two to eight sites eroded, some having had joint destruction of fusion. In the remaining eight no more than two ne sites of erosion were present. Occasionally erosion previously noted at five years was no longef present at 10 . However, usually additional site elsewhere were found to be eroded. The site $\overrightarrow{\text { Gे }}$ deterioration was variable, though further narrow

Table 1 Radiological change in peripheral joints five years after onset in 70 patients

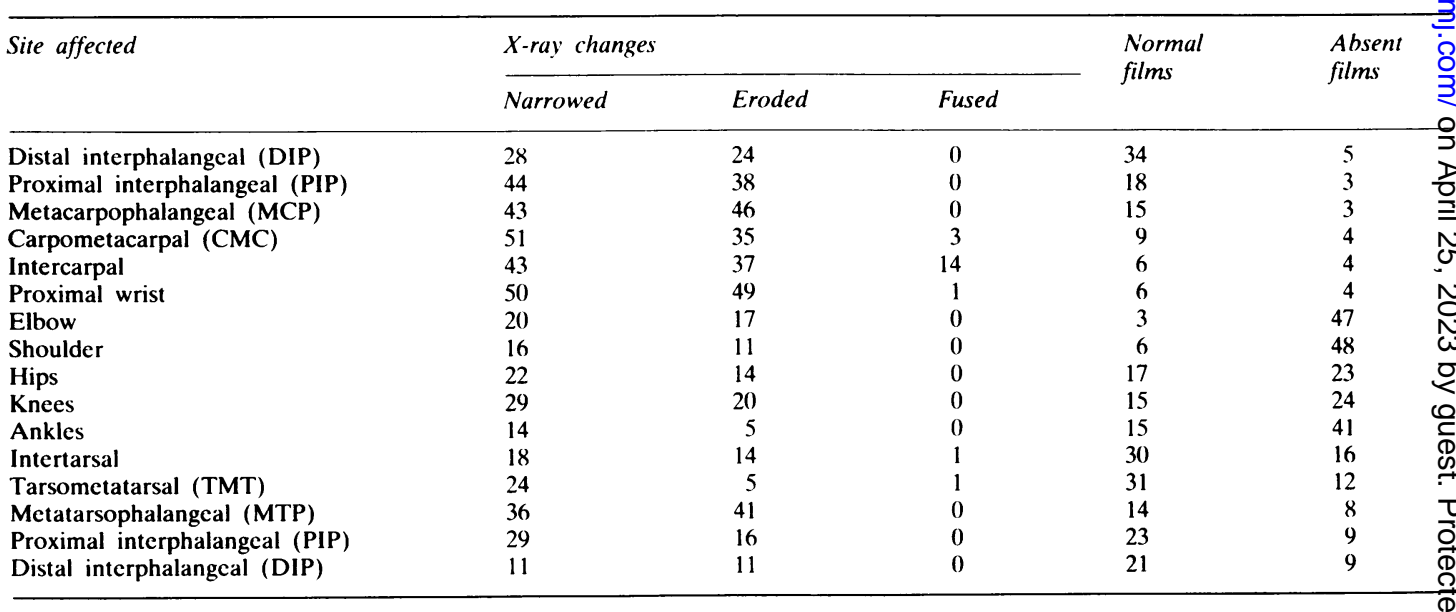




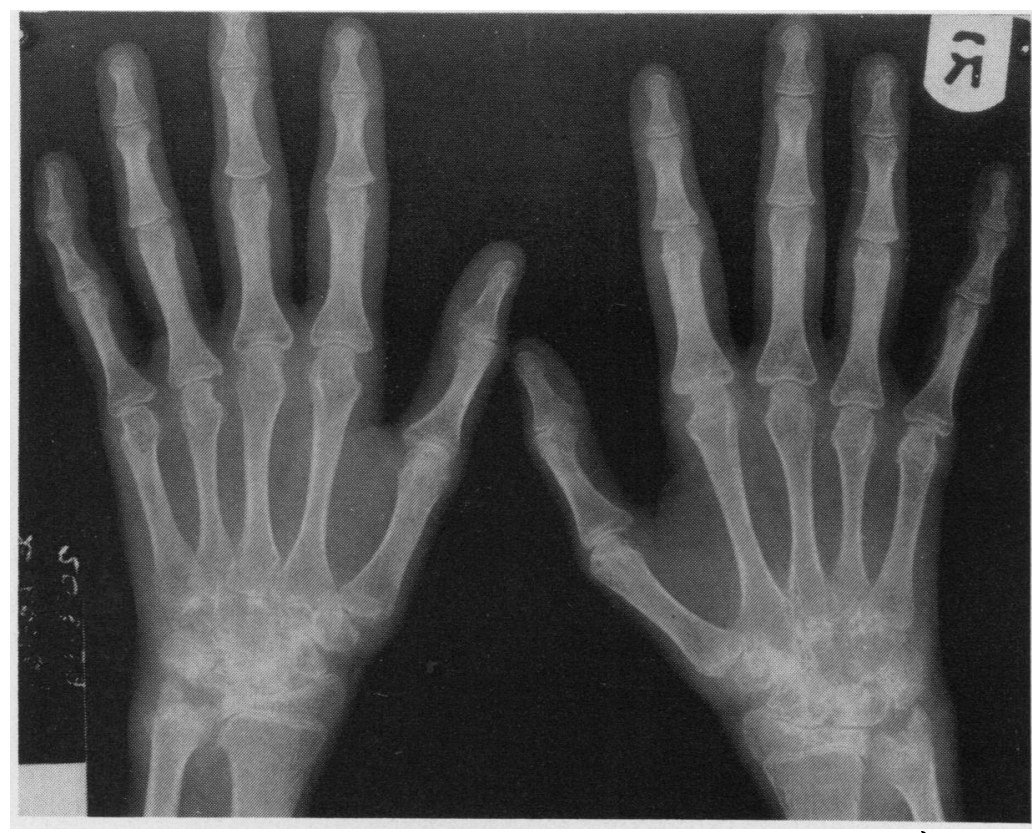

Fig. 1 Typical distribution of joints affected in the hand after five years of disease.

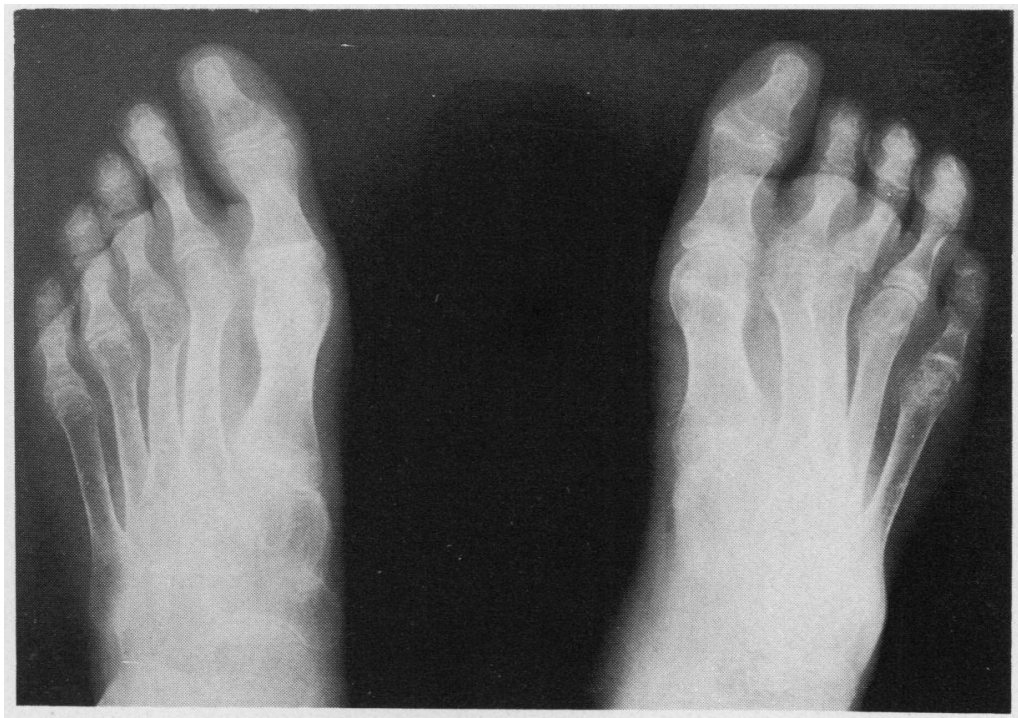

Fig. 2 Erosive change present in feet after five years of disease.

ing of the joint space was common at the DIP and MCP joints, and further erosive change was common at the PIP and MCP joints. Complete joint destruction had occurred at the DIP joint level in one patient, at the PIP joint level in two patients, at the MCP level in five, and at the proximal wrist in three patients. Bony fusion was still occurring at the CMC, carpal, or proximal wrist joints (Fig. 5). 


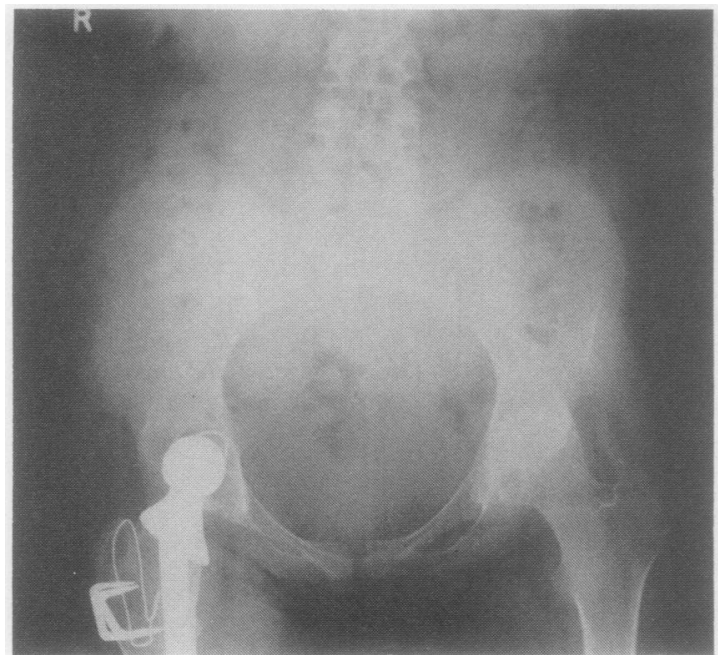

Fig. 3 Narrowed and eroded hip joints requiring replacement of the right hip after five years of disease.
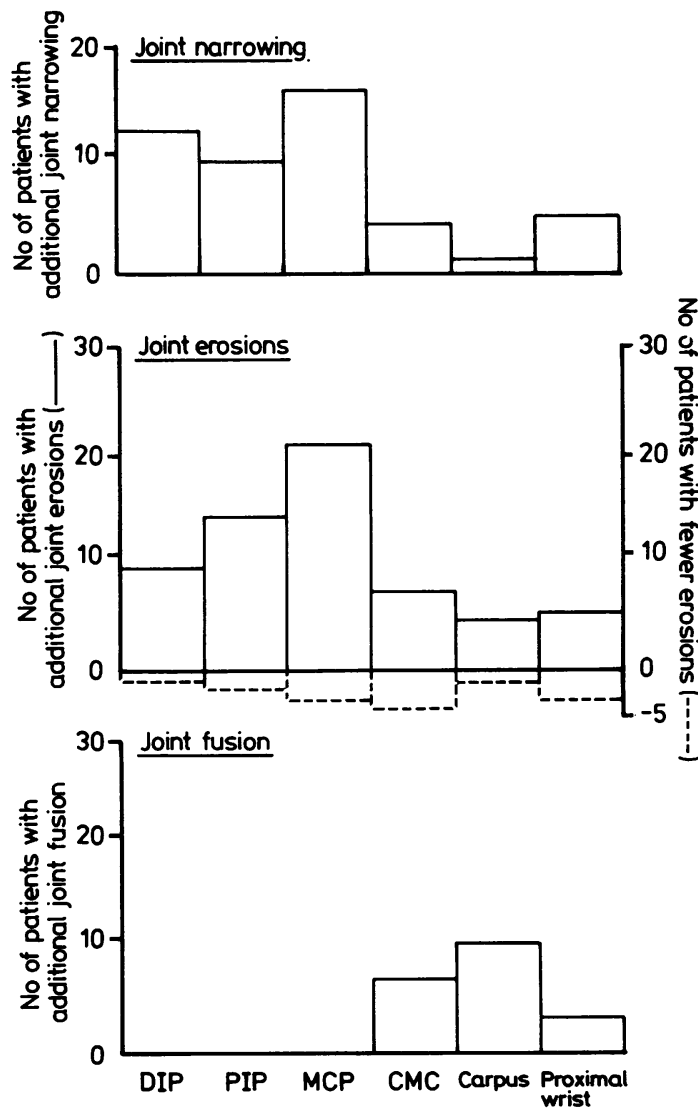

Fig. 4 Hand $x$-ray changes observed between five years and 10 years after onset of disease in 32 patients.
OVERALL RADIOLOGICAL CHANGE 10 YEAR FROM ONSET OF DISEASE

After 10 years of disease $x$-ray changes were usually more severe, and the number of radiologically normal joints seen was fewer than in those after five years of disease (Table 2). The distribution of peripheral joint damage was similar to that seen i $\bar{p}$ p earlier years. The most severely affected joints werब the hands and wrists, with fusion of carpal bones having occurred in half of the patients studied. Totall destruction of joints through erosion was seen ip four patients at the MCP joint, in three patients at the PIP joints, and in two patients each at the wristo elbow (Fig. 6), and DIP joint. Replacement of joints, sometimes bilaterally, had been made at thę hip and knee. Out of 41 patients in this 10-yeaf group seven patients had received a total of $12 \mathrm{hip}$ replacements and three patients had received tota knee replacements, one being bilateral.

RADIOLOGICAL CHANGE 15 YEARS AFTERO ONSET OF DISEASE

In the 19 sets of radiographs seen the pattern of join damage was similar to that present in patients after 10 years' disease duration; the commonest eroge $\vec{D}$ joints were still the wrist and MCP joint. No sites of fusion were evident. There were six totalfip replacements present in four patients, and bilateral total knee replacements had also beef performed. In 16 of these patients 10-year filmo were available for comparison. Little or no ado ditional erosive change was evident in 15; more that one additional joint was seen to be eroded in jusf one patient. In patients with severe disease normat growth of bone had been replaced by a slower an incomplete growing phase. The growth pattern were occasionally unbalanced, leading to additiona handicap in joint movement (Fig. 7). All of these factors combined with previous damage from in. flammation may cause abnormal wear with secons dary degenerative change (Fig. 8).

DRUG TREATMENT

Therapy with major drugs was given for periods o走. six months or longer to 54 patients out of the 81 if the series (Table 3). Our indication for use of second-line agents was that of erosive change of $x$-ray. Of the 49 patients receiving gold 10 had bee $\varphi^{2}$ treated within the first year of disease and 36 withio the first five years, though only 20 of these hat continued treatment for longer than six months. Th toxic effects which necessitated termination of the treatment were proteinuria in nine patients, rashes in six, and leucopenia in three. Other major dru宊 therapy was given at some stage in 39 patients 



Fig. $5 \mathrm{a}$

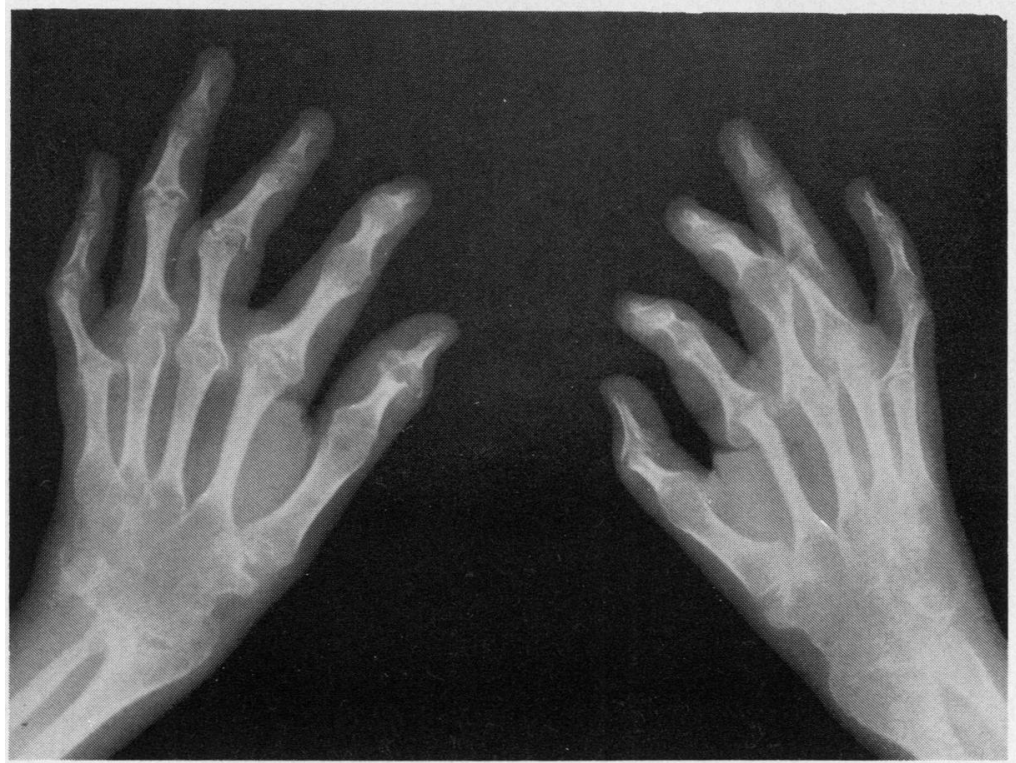

Fig. 5b
Fig. 5 Progression of erosive change especially at MCP joint level, with fusing carpal bones and retardation of growth: (a) after five years; (b) after ten years. usually in the form of prednisolone $(30)$, penicillamine (11), or chloroquine (11).

Of the 18 patients who received penicillamine three had started the drug in the first year of disease, and all had continued for at least six months. Twelve had started within five years of disease, nine of whom had continued it for at least six months. Five patients stopped the drug because of an adverse 
Table 2 Radiological change in peripheral joints 10 years after onset in 41 patients

\begin{tabular}{|c|c|c|c|c|c|}
\hline \multirow[t]{2}{*}{ Site affected } & \multicolumn{3}{|c|}{$X$-ray changes } & \multirow{2}{*}{$\begin{array}{l}\text { Normal } \\
\text { films }\end{array}$} & \multirow{2}{*}{$\begin{array}{l}\text { Absent } \\
\text { films }\end{array}$} \\
\hline & Narrowed & Eroded & Fused & & \\
\hline Distal interphalangeal (DIP) & 21 & 12 & 0 & 16 & 3 \\
\hline Proximal interphalangeal (PIP) & 30 & 25 & 0 & 5 & 3 \\
\hline Metacarpophalangeal (MCP) & 34 & 32 & 0 & 3 & 2 \\
\hline Carpometacarpal (CMC) & 28 & 24 & 9 & 0 & 3 \\
\hline Intercarpal & 17 & 23 & 21 & 0 & 2 \\
\hline Proximal wrist & 33 & 30 & 3 & 1 & 3 \\
\hline Elbow & 10 & 11 & 0 & 1 & 29 \\
\hline Shoulder & 6 & 5 & 0 & 0 & 34 \\
\hline Hips & 14 & 10 & 0 & 9 & 11 \\
\hline Knees & 18 & 13 & 0 & 2 & 17 \\
\hline Ankles & 3 & 2 & 0 & 6 & 32 \\
\hline Intertarsal & 15 & 6 & 1 & 7 & 17 \\
\hline Tarsometatarsal (TMT) & 14 & 2 & 4 & 7 & 16 \\
\hline Metatarsophalangeal (MTP) & 19 & 20 & 0 & 3 & 15 \\
\hline Proximal interphalangeal (PIP) & 17 & 5 & 0 & 4 & 15 \\
\hline Distal interphalangeal (DIP) & 7 & 6 & 0 & 6 & 15 \\
\hline
\end{tabular}

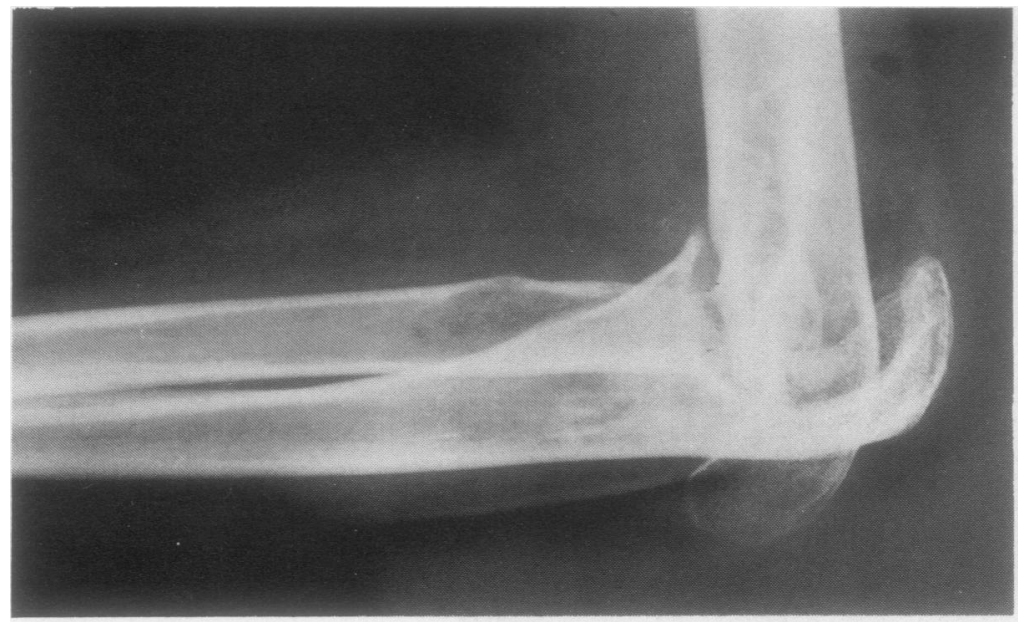

Fig. 6 Destruction of elbow $j$ thth after 10 years of disease.

reaction: gastrointestinal intolerance occurred in two, troublesome rashes occurred in two other patients, and severe proteinuria occurred in one. Twelve of these 18 patients also received gold at some stage, and eight also received prednisolone.

Twenty patients received some form of chloroquine. Six did so within a year of onset, and four of the six continued it for at least six months. Fifteen patients received treatment within five years of disease onset, with 10 completing more than six months' therapy. Three patients discontinued the drug because of side effects: nausea and a rash occurred in one patient, bleaching of hair in another, and retinal pigmentation occurred also in one patient. A combination of other major drug therapy was made at some stage in all but tw을
patients.

Oral steroid therapy was given to 50 patients usually in the form of prednisolone, and an ase. ditional 11 patients received ACTH injections. Thie average duration of therapy was 5.7 years in the first 15 years of their disease, though it was for less tham five years in 25 patients. Vertebral collapse occurred in four patients, steroid cataract in two.

Cytotoxic therapy was given to 11 patients, seveg of whom received azathioprine, four chlorambucin and two cyclophosphamide. Toxic side effects in cluded one episode of haematuria and hair loss afte尹 cyclophosphamide and two episodes of leucopenia

To help assess any possible therapeutic response 


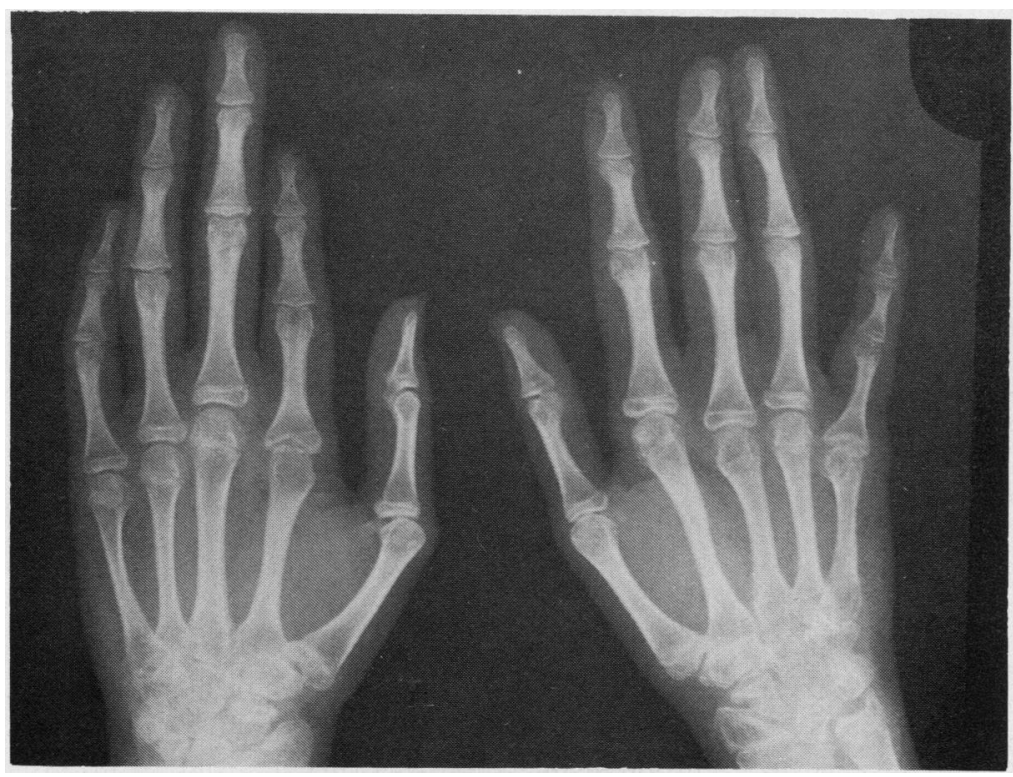

Fig. 7 Disproportionate retardation of growth affecting the fingers of both hands, particularly the right fifth and left index fingers.
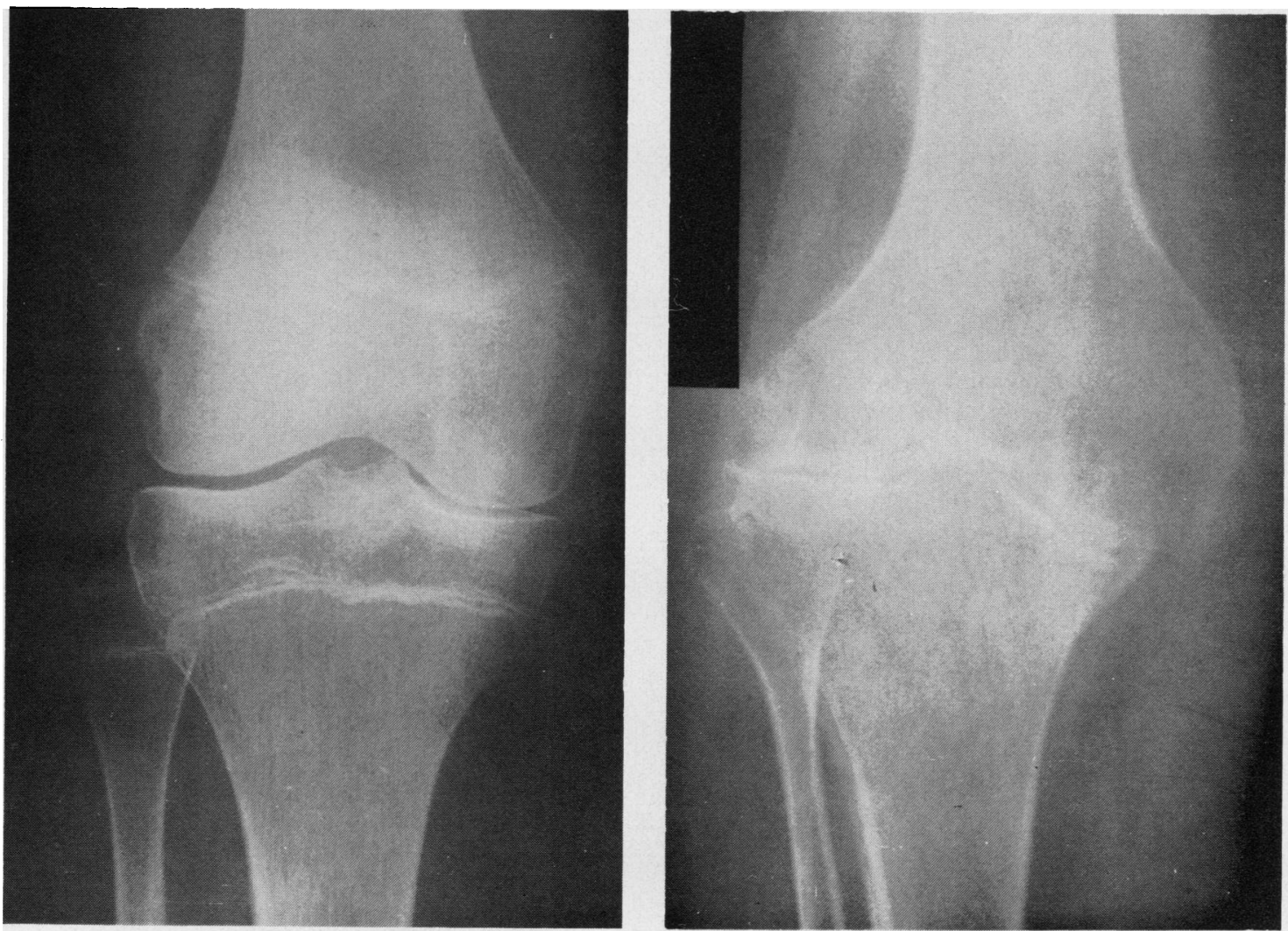

Fig. 8a

Fig. 8b

Fig. 8 (a) Moderate overgrowth of the femoral epiphysis as a factor in joint failure. (b) The joint 10 years later in the same patient. 
Table 3 Major anti-inflammatory drug therapy during the first 15 years of disease

\begin{tabular}{|c|c|c|c|c|}
\hline & $\begin{array}{l}\text { Number of patients } \\
\text { receiving the drug }\end{array}$ & $\begin{array}{l}\text { Number receiving the } \\
\text { drug for six months } \\
\text { or longer }\end{array}$ & $\begin{array}{l}\text { Adverse } \\
\text { reaction }\end{array}$ & $\begin{array}{l}\text { Number starting } \\
\text { therapy within } \\
\text { a year of onset }\end{array}$ \\
\hline Gold & 49 & 33 & 18 & 10 \\
\hline D-Penicillamine & 18 & 16 & 5 & 3 \\
\hline Chloroquine & 20 & 15 & 3 & 6 \\
\hline Oral steroids & 50 & 43 & 6 & 26 \\
\hline $\mathrm{ACTH}^{*}$ & 11 & 5 & 0 & 7 \\
\hline Cytotoxic drugs & 11 & 11 & 3 & 0 \\
\hline
\end{tabular}

${ }^{*} \mathrm{ACTH}=$ adrenocorticotrophic hormone.

to treatment the patients who had received nonsteroidal anti-inflammatory drugs (NSAIDs) alone were compared with those who had been treated with either single or multiple major drug therapy. It was found that severe progression of $x$-ray changes might occur with or without major drug treatment, and no individual drug or combination of drugs was of obvious benefit. In general terms patients with severe disease would usually continue to deteriorate with or without major drug therapy, while the exceptionally mildly affected child might continue without significant deterioration on simple medication.

DRUG THERAPY IN PATIENTS WITH SEQUENTIAL HAND X-RAYS AT FIVE AND 10 YEARS AFTER ONSET

Treatment varied from salicylates alone, to a range of NSAIDs, to oral steroids (19 patients), gold (eight patients), penicillamine (three patients), hydroxychloroquine (two patients), cyclophosphamide (one patient), and ACTH (one patient). Eleven of these 32 patients received more than one of the stronger drugs. Nine patients received only NSAIDs. Any possible relationship of $x$-ray changes to major drug therapy were looked for individually, but there seemed no pattern of successful drug treatment for the period under review.

\section{Discussion}

The radiological similarity to adult patients with seropositive rheumatoid arthritis is obvious from the results, though this was a retrospective study and adult disease has been subject to more intensive and prospective study. ${ }^{5}$ An additional problem when assessing juveniles is that of poor growth in the presence of persistent systemic disease activity which can add to the local effect of arthritis in stunting growth.

The severe and widespread radiological change evident after five years supports the concept of earlys damage. However, significant progression of diseas $\overrightarrow{5}$ continued over the next five years so that by 10 year: from onset there were widespread erosions in the small finger joints and some complete joint destruc? tion. $50 \%$ of children were found to have bony fusion at the wrist. The sites affected at this stag\& showed a distribution of changes similar to aduli disease with the additional features of more como mon DIP joint erosion and fusion of the carpal bones. At later stages of disease problems requirong surgery were more evident due to various mechor cal difficulties often secondary to poor growth क्षुछ degenerative change and to the primary destructive arthritis. The effect of drug treatment on the natura history of the condition is difficult to assess, sincö there was a spectrum of disease severity, with a few patients remaining stable. Many different treat: ments were tried, though often at a time whe present day drugs such as penicillamine were no플 available. Others such as gold now tend to be use earlier and given for longer periods. In addition some patients were referred several years after onse of disease. Published work on the effects of gold ang penicillamine and other second-line drugs in adufy disease has shown some evidence of reduced rate of disease progression on $x$-ray. ${ }^{6}$ Further studies of prospective nature are urgently required, particularly in children with seropositive disease, since this subgroup of juvenile chronic arthritis must represert. one of the worst prognosis groups of patients witff arthritis.

The administrative help from Pat Spencer, the photography works of Jean Tyler and Barry Wilks, and the typing of the manuscript by Gloria Gray are all gratefully acknowledged.

\section{References}

1 Ansell B M. Wood P H N. In: Ansell B M. ed. Clinics in rheumatic diseases. Oxford: Saunders, 1976: 402.

2 Ansell B M, Rheumatic disorders in childhood (Postgraduat paediatric series). London: Butterworth, 1980: Chap. 4. 
3 Clemens L E, Albert E, Ansell B M. HLA associations in IgM rheumatoid factor positive chronic arthritis in childhood. Ann Rheum Dis 1982; 41: 195.

4 Greulich W W, Pyle S I. Radiographic atlas of skeletal development of the hand and wrist. London: Oxford University Press, 1959.
5 Winfield J, Young A, Williams P. Corbett M. Prospective study of the radiological changes in hands, feet, and cervical spine in adult rheumatoid disease. Ann Rheum Dis 1983; 42: 613-8.

6 Scott D L, Grindulis K A. Struthers G R. Coulton B L, Popert A J, Bacon P A. Progression of radiological change in rheumatoid arthritis. Ann Rheum Dis 1984; 43: 8-17.

\section{Book reviews}

Mathematical Models in Medical Diagnosis. By $M$ Clinton Miller III, Milton C Westphal Jr, John Routt Reigart II. Pp. 187. £25·50. Praeger: New York. 1981.

This book is unlikely to be directly helpful to the clinician. Apart from a reasonable explanation of the principles of cluster analysis, the general approach is very mathematical and abstract. Even for those whose interests lie in the manipulation of clinical data much of the book might prove hard going.

Statisticians, on the other hand, will find that each chapter ends just when the mathematical problems become interesting.

Bone and Joint Research Unit, The London Hospital Medical College

J R KIRWAN

Arthritis and Allied Conditions. 10th edn. Ed. Daniel J McCarty. Pp. 1750. US $\$ 121 \cdot 00$. Lea and Febiger: Philadelphia. 1985.

Rheumatologists who like to keep their reference books up to date may regret that those responsible for producing the two major North American texts did not contrive to stagger the two new editions. As it is, this 10th edition of 'Hollander' arrives almost simultaneously with the second edition of the large textbook edited by Kelley, Harris, Ruddy, and Sledge. The editors on the other hand will, I suspect, give a hollow laugh at the suggestion that it lies within their power to control accurately when the books will appear.

The cover of this new edition is in gold. Curiously this is not to celebrate its 50th birthday, for the first edition of 'Comroe' appeared in 1940. It is, as Dan McCarty explains in his Preface 'to symbolise the current status of the clinical discipline'. However, while seeking to present the very latest state of the specialty, the past is not forgotten, and the Foreword is written by the distinguished previous editor, Dr Joseph Lee Hollander. His account of why he gave up after editing five editions has parallels with the hesitation of composers about completing a ninth symphony! Dr Hollander also contributes two chapters. In arguing again the case for the value of local corticosteroid injections he is now able to quote his personal experience of over 400000 injections in over 12000 patients during more than 32 years: 'No other form of treatment for arthritis has given such consistent local symptomatic relief to so many for so long with so few harmful effects'.

How well does this large textbook serve its purpose? I have now had it on my shelf for six weeks and have used it both to browse and to check particular points, and I find it good - through and through. The size has crept up to nearly 1800 pages, but the publishers remarkably have succeeded in producing a volume which is manageable in the hand and which does not appear likely to start splitting out of its cover with use. The style of printing and layout are clear, and the illustrations mainly very adequate. A considerable improvement on previous editions is the more complete style of the references, giving both title and pagination.

As with previous editions this one provides a satisfactory balance between scientific background, systematic accounts of rheumatic diseases, and related laboratory and management matters. Two great virtues of this book are that, despite being very comprehensive, there is remarkably little overlap between authors, and the style of the writing is mainly excellent. By and large even the more basic scientific chapters are written sufficiently clearly and simply for the general reader to enjoy them. Reading about highly technical subjects can become very tedious when excessive use of jargon and abbreviations replaces clarity and simplicity. Fortunately there is very little of that in this book.

Is there anything to criticise? The only fault I could find concerned the index. Consulting the index is the starting point for much of the use that is made of a volume like this, so it should be good. Unfortunately most large multiauthor textbooks are indexed (as in this case, I suspect) by the publishers, who do not have the authors' insight into which words should be included. To take one small example at random: in Mart Mannik's excellent chapter on rheumatoid factors the author would have been in no doubt that the word 'antiglobulin' might provide a lead in to his subject for someone unfamiliar with the topic. Yet it does not appear in the index. I believe that good indexing is a neglected skill in medical publishing. In a multiauthor text there would appear to be excellent reasons for asking all authors to mark in their manuscripts each and every word that should appear in the index. The publisher can then do the rest.

However, the overall verdict must be that this edition represents a resounding triumph for both editor and publisher. No English speaking rheumatologist will want to be without ready access to a copy, and its usefulness will extend well beyond the specialty.

H L F CURREY 